\title{
Assessment of the Possibility of Radiation Dermatitis in the Legs of Interventional Radiologists
}

\author{
Fariba Zarei, ${ }^{1}$ Banafsheh Zeinali-Rafsanjani, ${ }^{2}$ Mahdi Saeedi-Moghadam, ${ }^{1}$ Alireza Rasekhi, ${ }^{1,}{ }^{*}$ and Amin \\ Abolhasani Foroughi ${ }^{1}$ \\ ${ }^{1}$ Medical Imaging Research Center, Shiraz University of Medical Sciences, Shiraz, Iran \\ ${ }^{2}$ Nuclear Medicine and Molecular Imaging Research Center, Shiraz University of Medical Sciences, Shiraz, Iran \\ "Corresponding author: Alireza Rasekhi, Medical Imaging Research Center, Shiraz University of Medical Sciences, Shiraz, Iran. E-mail: dr.alirezarasekhi@gmail.com
}

Received 2016 October 08; Revised 2017 March 07; Accepted 2017 April 16.

\begin{abstract}
Background: Fluoroscopy guided imaging, which is going to be more routine these days, requires a long time of fluoroscopic observing that could increase the radiation dose of the physician and other staff who have to stay near the patient during the procedure. In our department, one of the senior interventionists observed hair loss in his lower limb.

Objectives: The objective of this study was to measure the radiation dose of the physician's leg during common procedures in order to find out that whether the radiation dose exceeds the threshold of deterministic effects of radiation.

Patients and Methods: Thermoluminescent-dosimeters (TLD-100) set on the leg part of the anthropomorphic whole body phantom PBU-50 was used in order to measure the radiation dose in two centers where our interventionist worked. Meanwhile, the duration of exposure in important procedures was observed and recorded in center 1 for 2 months. During this period, data including age, height, and weight of the patients, and radiation exposure time, dose (mGy) and dose area product (dap) $\left(\mu \mathrm{Gy} . \mathrm{cm}^{2}\right)$ were recorded.

Results: The result of TLD dosimetry showed that the mean effective dose in center 1 and 2 was 0.20 and $0.86 \mathrm{mSv}$, and also the mean-dose $(\mathrm{mSv}) / \mathrm{min})$ in these centers was $0.02 \pm 0.00$ and $0.20 \pm 0.015 \mathrm{mSv} / \mathrm{min}$, respectively.

Conclusion: The effective annual dose of interventionists who work in center 1 and 2 was 143.08 and 1226.78 mSv, respectively. The high radiation dose delivered to the leg of physicians in center 2 could be an important cause of radiation dermatitis occurred on the leg of our interventionist. Patient dose during most of the procedures was less than the threshold dose for occurring erythema. However, unfortunately in transjugular intrahepatic portosystemic shunt (TIPS) procedure, which is a time-consuming procedure, the patient radiation dose exceeds the threshold. It would be useful if a plan was designed to reduce the dose of patients and even physicians.
\end{abstract}

Keywords: Radiation Dose, Leg, Occupational Dose, Interventional Radiology

\section{Background}

Recently, application of fluoroscopy-guided imaging is increasingly growing. This is the result of development in medical technology, which in turn improves powerful $\mathrm{X}$-ray equipment for complicated procedures that need fluoroscopy guidance such as interventional procedures, which were rarely accomplished in the past $(1,2)$.

These procedures typically need a long time of fluoroscopic observing that could increase the radiation dose of patients and staff. During interventional radiology procedures, the physician and other staff have to stay near the patient; therefore, they are exposed to a large amount of scattered radiation as well. Interventionists can also achieve more radiation from primary or leakage radiation as well. For instance, their hands enter the primary X-ray beam and their lower extremities are close to the X-ray tube. This may lead to leakage radiation dose $(3,4)$.
While the vital parts of the body can be separately protected by lead or non-lead aprons $(5,6)$, the extremities especially the legs remain practically unprotected. Consequently, it is essential to confirm that the annual dose limits are not exceeded (7).

There are some reports that have revealed that radiation doses to the legs of interventionists were more than the radiation dose to the hands. Among interventionists, there are reports of leg hair loss due to prolonged occupational radiation exposure, which is called radio-dermatitis (7-10). Considering these events, studies have previously checked the radiation dose of the leg and reported that when the leg is unprotected and the equipment mounted protectors are absent, the radiation dose of the leg could exceed the threshold dose of radiation-induced skin damage $(7,8,11-13)$.

Chronic occupational dermatitis primarily results in 
dry, shiny and hairless skin with atrophy of the epidermis. Other symptoms such as ulceration, fibrosis, and subsequent squamous cell carcinoma may also be observed. The accumulative radiation dose required to cause chronic alterations are beyond 10 - 12 Gy. In our department, one of the senior interventionists had observed hair loss in his lower limb. It means he received more than 10 Gy of radiation during his work in all these years (14-16).

\section{Objectives}

Considering that the mentioned interventionist worked in two centers, we were encouraged to check the radiation dose of the physician's leg via thermoluminescent dosimeter (TLD-100) in both centers. Thus, the objective of this study was to measure the radiation dose of the physician's leg during common procedures in order to find out whether the radiation dose exceeded the threshold of deterministic effects of radiation. It should be noted that deterministic effects of radiation are the effects that definitely occur after receiving a certain amount of the radiation in people such as Erythema, Cataract, and permanent sterility which occur after 2 Sv, 2 - 10 Gy and 2.5 - 3.5 Gy respectively.

\section{Patients and Methods}

TLD-100 was used to measure the radiation dose since it is a routine dosimeter in the clinic and there are many studies that used this dosimeter (17-20). Since it was predicted that interventionists might forget to set the dosimeters on their leg before the procedure, a phantom study was performed. The leg part of the anthropomorphic whole body phantom (PBU-50), which is in life-size, was used. Three TLDs were packed in a packet and fixed on the leg phantom in the same location that the deterministic effects were observed in the senior interventionist. Then, the phantom was located near the place the interventionists usually stand during the procedure. Figure 1 shows the position of the phantom and the physician.

The phantom was irradiated simultaneously with the interventionist during his work with patients for a working day. Another set of TLD with the same characteristics was prepared and fixed on the phantom and irradiated in the same situation as center 1 in center 2 . The measurements achieved with dosimeters were corrected for operational quantity $\mathrm{HP}(0.07)$ and the mean dose $(\mathrm{msv} / \mathrm{min})$ was calculated.

The duration of radiation exposure in specific procedures, which in turn determines the interventionist's standing time bedside the patient during irradiation was

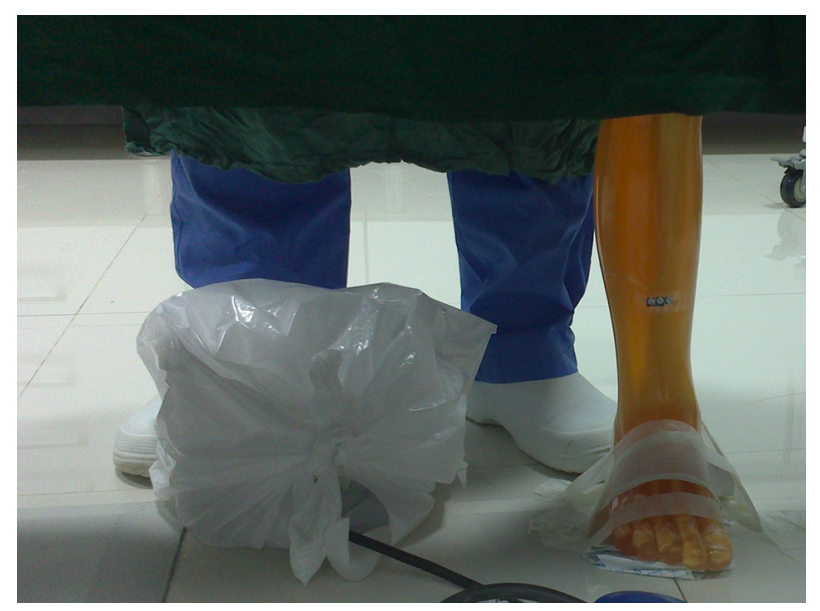

Figure 1. The position of the phantom and the physician

observed and recorded in center 1 for 2 months. During this period of time, the characteristics of patients and procedures (86 patients) were gathered. The recorded information included age, height, and weight of the patients and radiation exposure time, dose (mGy) and dose area product (dap) $\left(\mu \mathrm{Gy} . \mathrm{cm}^{2}\right)$. In order to assess the dose received by the patient in cerebral and hepatic angiographies, air kerma-area product $\left(\mathrm{P}_{\mathrm{KA}}\right)$ was obtained from the value provided by the equipment considering the geometry of irradiation and exposure parameters selected during the clinical procedure. Using these data, the average time of important procedures such as four vessels, six vessels cerebral angiography, extended percutaneous transhepatic biliary drainage (PTBD), trans-arterial chemoembolization(TACE), transjugular intrahepatic portosystemic shunt (TIPS) and portal vein embolization (PVE) were recorded and assessed. This information can be used to calculate leg dose/procedure, we could also provide an estimation of the patient dose.

\section{Results}

The result of TLD dosimetry showed that the mean effective dose in center 1 and 2 was $0.20 \pm 0.33$ and $0.86 \pm 1.17$ $\mathrm{mSv}$, respectively, and also the mean dose in these centers was $0.02 \pm 0.00$ and $0.20 \pm 0.015(\mathrm{mSv} / \mathrm{min})$, respectively. The details of 2 months monitoring of interventional procedures on 86 patients are demonstrated in Table 1.

The results of data gathering during 2 months and the calculated leg dose per procedure are summarized in Table 2. 
Table 1. Number of Brain and Hepatic Interventional Procedures and the Details of Patient Information in Each Group of Procedures ${ }^{\mathrm{a}}$

\begin{tabular}{lccc}
\hline Procedure & Number of Patients & Mean Age & Mean Height \\
\hline Brain & 56 & $54.69 \pm 19.78$ & $166.07 \pm 8.65$ \\
Hepatic & 30 & $49.11 \pm 18.86$ & $166.64 \pm 9.43$ \\
\hline
\end{tabular}

${ }^{\mathrm{a}}$ Values are expressed as mean $\pm \mathrm{SD}$.

Table 2. Time, Dose and Dose Area Product (DAP) of Each Procedure in Conjunction with Leg Dose of Physicians During the Procedure ${ }^{\mathrm{a}}$

\begin{tabular}{|c|c|c|c|c|c|c|c|c|}
\hline Procedure & Mean Time & SD Time & $\begin{array}{c}\text { Mean } \\
\text { Dose, mGy }\end{array}$ & $\begin{array}{c}\text { Mean } \\
\text { Dose, } \\
(\mathrm{mGy}) / \mathrm{min}\end{array}$ & SD Dose & Mean DAP, $\left(\mu\right.$ Gy. $\left.\mathbf{m}^{2}\right) / \mathrm{min}$ & SD DAP & $\begin{array}{l}\text { Leg dose, } \\
\text { mSv/pro }\end{array}$ \\
\hline \multicolumn{9}{|l|}{ Brain pro } \\
\hline 4vessels & 11.47 & 7.17 & 600.39 & 74.18 & 50.11 & 949.58 & 632.57 & 0.15 \\
\hline 6vessels & 12.21 & 5.86 & 789.56 & 73.60 & 20.91 & 991.52 & 277.98 & 0.28 \\
\hline \multicolumn{9}{|l|}{$\begin{array}{l}\text { Hepatic } \\
\text { pro }\end{array}$} \\
\hline PTBD & 6.78 & 5.72 & 301.99 & 40.15 & 12.62 & 252.24 & 82.81 & 0.16 \\
\hline TACE & 11.66 & 8.41 & 956.83 & 68.58 & 24.65 & 582.50 & 422.65 & 0.27 \\
\hline TIPS & 51.76 & 26.83 & 2032.0 & 46.56 & 14.08 & 304.94 & 49.03 & 1.19 \\
\hline PVE & 13.16 & 1.48 & 506.50 & 40.25 & 15.65 & 200.53 & 8.91 & 0.30 \\
\hline
\end{tabular}

Abbreviations : Pro, procedure; PVE, portal vein embolization; PTBD, percutaneous transhepatic biliary drainage; SD, Standard Deviation; TACE, trans-arterial chemoembolization; TIPS, transjugular intrahepatic portosystemic shunt.

${ }^{\mathrm{a}}$ The DAP and radiation dose during the procedure were obtained from the system.

\section{Discussion}

Having observed the radiation dermatitis on the leg of senior interventionist, a plan was designed to perform radiation dosimetry of the physician's leg during interventional procedures in both centers where these specialists worked. A phantom and TLD dosimetry study was performed with the purpose of evaluating the radiation dose of physician's leg as well as estimating the annual effective dose of interventionists. Meanwhile, it provided a proper opportunity to gather statistical information of patients and make an estimation of their received dose.

According to the results, radiation doses of leg were $0.02 \mathrm{mSv}$ in center 1 and $0.20 \mathrm{mSv}$ in center 2 , which is 10 fold the amount of center 1 . This difference between centers can be attributed to the equipment that these centers use for interventional radiology. The table of center 1 had a protective lead curtain. Despite the difficulties in its moving, it was effective in decreasing the radiation dose of the legs. The table in center 2 did not have any lead curtain.

According to Table 2, the radiation dose of leg in both centers agrees with previous studies. The effective dose of leg in center $1(0.2 \mathrm{mSv})$ is in the range of the estimated values in previous studies, but the effective dose in center 2 that did not have the protective curtain was close to the results of the study conducted by Koukorava et al. (11) when they did not use equipment mounted protectors (Table 3 ).

The radiation dose of leg in center 1 was a little high,
Table 3. Estimated Dose of Legs in Previous Studies

\begin{tabular}{lc}
\hline Dose of leg in Interventional Radiology (other studies) & Mean, mSv \\
\hline F. Vanhavere et al. 2006 (13) & 0.05 \\
\hline C. P. Shortt et al. 2007 (12) & 0.23 \\
\hline C. Koukorava et al. 2011 (11) & 0.60 \\
\hline E. Efstathopoulos et al. 2014 (8) & 0.14 \\
\hline M. Whitby et al. 2014 (7) & 0.20 \\
\hline
\end{tabular}

but comparable to the other studies. For instance, in our study, the radiation dose of physician's leg in TIPS and PTBD were 1.19 and $0.16 \mathrm{mSv} /$ pro, respectively, which agree with the radiation dose of leg per TIPS and percutaneous transhepatic cholangiogram (PTC) in the study performed by Efstathopoulos et al., which was 1.96 and $0.22 \mathrm{mSv} / \mathrm{pro}$, respectively (8).

The international commission of radiological protection (ICRP) suggests that the annual dose limit of extremities should be less than $500 \mathrm{mSv}$ in order to restrict the risk of erythema and temporary epilation. The ionizing radiations regulations (IRR) also recommended identifying the radiation workers whose doses exceeding three-tenth of the dose limit suggested by ICRP, which is $150 \mathrm{mSv}$ for the extremities.

The effective annual dose of interventionists who work 
in center 1 and 2 was calculated as 143.08 and $1226.78 \mathrm{mSv}$, respectively. According to the aforementioned regulation, the radiation dose of leg in center 1 does not require special monitoring, but in center 2 plans should be considered to reduce the leg radiation dose. The high radiation dose which is delivered to the leg of physicians in center 2 could be an important cause of radiation dermatitis occurred on the leg of our interventionist. According to the estimations, even if the interventionist just works $15 \mathrm{~min}$ with radiation, his effective dose is a little higher than 150 mSv.

Patient dose during most of the procedures was less than 2 Gy, which is the threshold dose for occurring erythema, but unfortunately, in TIPS, which is a timeconsuming procedure, the patient radiation dose exceeds 2 Gy, which causes erythema. It would be useful if a plan was designed to reduce the dose of patients and even physicians.

\section{Footnotes}

Authors' Contributions: None declared.

Financial Disclosure: None declared.

Funding/Support: None declared.

\section{References}

1. Balter S, Hopewell JW, Miller DL, Wagner LK, Zelefsky MJ. Fluoroscopically guided interventional procedures: a review of radiation effects on patients' skin and hair. Radiology. 2010;254(2):326-41. doi: 10.1148/radiol.2542082312. [PubMed: 20093507].

2. Miller DL, Balter S, Schueler BA, Wagner LK, Strauss KJ, Vano E. Clinical radiation management for fluoroscopically guided interventional procedures. Radiology. 2010;257(2):321-32. doi: 10.1148/radiol.10091269. [PubMed: 20959547].

3. Wagner LK, McNeese MD, Marx MV, Siegel EL. Severe skin reactions from interventional fluoroscopy: case report and review of the literature. Radiology. 1999;213(3):773-6. doi: 10.1148/radiology.213.3.r99dc16773. [PubMed:10580952].

4. Dendy PP. Radiation risks in interventional radiology. $\mathrm{Br}$ J Radiol. 2008;81(961):1-7. doi: 10.1259/bjr/15413265.

5. Kazempour M, Saeedimoghadam M, Shekoohi Shooli F, Shokrpour N. Assessment of the Radiation Attenuation Properties of Several Lead Free Composites by Monte Carlo Simulation. J Biomed Phys Eng. 2015;5(2):67-76. [PubMed: 26157732].
6. Haghighatafshar M, Rezaie P, Atefi M, Gheisari F, Okhovat M. Design of a Novel Shield of Nuclear Medicine with New Alloy. Phys Sci Int J 2015;7(1):28-32. doi: 10.9734/psij/2015/16603.

7. Whitby M, Martin CJ. Radiation doses to the legs of radiologists performing interventional procedures: are they a cause for concern? Br J Radiol. 2003;76(905):321-7. doi: 10.1259/bjr/65778215. [PubMed: 12763947].

8. Efstathopoulos EP, Pantos I, Andreou M, Gkatzis A, Carinou E, Koukorava $\mathrm{C}$, et al. Occupational radiation doses to the extremities and the eyes in interventional radiology and cardiology procedures. $\mathrm{Br} \mathrm{J} \mathrm{Ra-}$ diol. 2011;84(997):70-7. doi: 10.1259/bjr/83222759. [PubMed: 21172967].

9. Rehani MM, Srimahachota S. Skin injuries in interventional procedures. Radiat Prot Dosimetry. 2011;147(1-2):8-12. doi:10.1093/rpd/ncr257. [PubMed: 21737442].

10. Alahmari MA, Sun Z, Bartlett A. Radiation Protection in an Interventional Laboratory: A Comparative Study of Australian and Saudi Arabian Hospitals. Radiat Prot Dosimetry. 2016;172(4):453-65. doi: 10.1093/rpd/ncv547. [PubMed: 26838067].

11. Koukorava C, Carinou E, Simantirakis G, Vrachliotis TG, Archontakis E, Tierris C, et al. Doses to operators during interventional radiology procedures: focus on eye lens and extremity dosimetry. Radiat Prot Dosimetry. 2011;144(1-4):482-6. doi:10.1093/rpd/ncq328. [PubMed: 21044993].

12. Shortt CP, Al-Hashimi H, Malone L, Lee MJ. Staff radiation doses to the lower extremities in interventional radiology. Cardiovasc Intervent Radiol. 2007;30(6):1206-9. doi: 10.1007/s00270-007-9071-0. [PubMed: 17533541].

13. Vanhavere F, Berus D, Buls N, Covens P. The use of extremity dosemeters in a hospital environment. Radiat Prot Dosimetry. 2006;118(2):1905. doi: 10.1093/rpd/ncl017. [PubMed:16581921].

14. Bepko J, Mansalis K. Common Occupational Disorders: Asthma, COPD, Dermatitis, and Musculoskeletal Disorders. Am Fam Physician. 2016;93(12):1000-6. [PubMed: 27304769].

15. Kim DH, Kim HS, Lee JY, Park HJ, Cho BK. A case of chronic radiodermatitis with CML and squamous cell carcinoma in radiologist. Ann Dermatol(Seoul). 2006;18(1):9-13. doi:10.5021/ad.2006.18.1.9.

16. Wiper A, Katira R, Roberts DH. Images in cardiology. Interventional cardiology: it's a hairy business. Heart. 2005;91(11):1432. doi: 10.1136/hrt.2005.064899. [PubMed:16230441].

17. Faghihi R, Mehdizadeh S, Sina S, Alizadeh FN, Zeinali B, Kamyab GR, et al. Radiation dose to neonates undergoing X-ray imaging in special care baby units in Iran. Radiat Prot Dosimetry. 2012;150(1):55-9. doi: 10.1093/rpd/ncr373. [PubMed: 22128357].

18. Sina S, Zeinali B, Karimipoorfard M, Lotfalizadeh F, Sadeghi M, Zamani $\mathrm{E}$, et al. Investigation of the entrance surface dose and dose to different organs in lumbar spine imaging. J Biomed Phys Eng. 2014;4(4):11926. [PubMed: 25599058].

19. Gavala S, Donta C, Tsiklakis K, Boziari A, Kamenopoulou V, Stamatakis HC. Radiation dose reduction in direct digital panoramic radiog raphy. Eur J Radiol. 2009;71(1):42-8. doi: 10.1016/j.ejrad.2008.03.018. [PubMed: 18448296].

20. Maia AF, Caldas LV. Response of TL materials to diagnostic radiology X radiation beams. Appl Radiat Isot. 2010;68(4-5):780-3. doi: 10.1016/j.apradiso.2010.01.002. [PubMed: 20097569]. 